\title{
Publisher Correction: Barcoding reveals complex clonal behavior in patient-derived xenografts of metastatic triple negative breast cancer
}

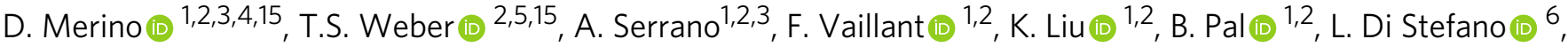 \\ J. Schreuder (1) 2,5,7, D. Lin (1) 2,5,7, Y. Chen (1) 2,6, M.L. Asselin-Labat (1) 1,2, T.N. Schumacher (1) ${ }^{8}$, D. Cameron (1) ${ }^{6}$, \\ G.K. Smyth (1) 6,9, A.T. Papenfuss (10) $2,6,9,10,11$, G.J. Lindeman (iD) $1,12,13,14$, J.E. Visvader (iD) $1,2,16$ \& S.H. Naik (iD) $2,5,7,16$
}

Correction to: Nature Communications https://doi.org/10.1038/s41467-019-08595-2, published online 15 February 2019

The original version of this Article contained an error in Fig. 4. In the left histogram of the right panel of Fig. 4d, several data points were inadvertently deleted from the histogram during the production process. This error has been corrected in both the PDF and HTML versions of the Article. The original, incorrect version of Fig. 4 is presented below as Fig. 1.

Published online: 24 April 2019

(i) Open Access This article is licensed under a Creative Commons Attribution 4.0 International License, which permits use, sharing, adaptation, distribution and reproduction in any medium or format, as long as you give appropriate credit to the original author(s) and the source, provide a link to the Creative Commons license, and indicate if changes were made. The images or other third party material in this article are included in the article's Creative Commons license, unless indicated otherwise in a credit line to the material. If material is not included in the article's Creative Commons license and your intended use is not permitted by statutory regulation or exceeds the permitted use, you will need to obtain permission directly from the copyright holder. To view a copy of this license, visit http://creativecommons.org/licenses/by/4.0/.

(C) The Author(s) 2019

\footnotetext{
${ }^{1}$ ACRF Stem Cells and Cancer Division, The Walter and Eliza Hall Institute of Medical Research, Parkville, VIC 3052, Australia. ${ }^{2}$ Department of Medical Biology, The University of Melbourne, Melbourne, VIC 3010, Australia. ${ }^{3}$ Olivia Newton-John Cancer Research Institute, Heidelberg, VIC 3084, Australia. ${ }^{4}$ School of Cancer Medicine, La Trobe University, Bundoora, VIC 3086, Australia. ${ }^{5}$ Molecular Medicine Division, The Walter and Eliza Hall Institute of Medical Research, Parkville, VIC 3052, Australia. ${ }^{6}$ Bioinformatics Division, The Walter and Eliza Hall Institute of Medical Research, Parkville, VIC 3052 , Australia. ${ }^{7}$ Immunology Division, The Walter and Eliza Hall Institute of Medical Research, Parkville, VIC 3052, Australia. ${ }^{8}$ Division of Molecular Oncology \& Immunology, Netherlands Cancer Institute, Amsterdam 1066 CX, The Netherlands. ${ }^{9}$ School of Mathematics and Statistics, The University of Melbourne, Melbourne, VIC 3010, Australia. ${ }^{10}$ Peter MacCallum Cancer Centre, Melbourne, VIC 3000, Australia. ${ }^{11}$ Sir Peter MacCallum Department of Oncology, University of Melbourne, Melbourne, VIC 3010, Australia. ${ }^{12}$ Department of Medical Oncology, The Peter MacCallum Cancer Centre, Melbourne, VIC 3000, Australia. ${ }^{13}$ Department of Medicine, The University of Melbourne, Melbourne, VIC 3010, Australia. ${ }^{14}$ Parkville Familial Cancer Centre, The Royal Melbourne Hospital and Peter MacCallum Cancer Centre, Parkville, VIC 3050, Australia. ${ }^{15}$ These authors contributed equally: D. Merino, T. S. Weber. ${ }^{16}$ These authors jointly supervised this work: J. E. Visvader, S. H. Naik. Correspondence and requests for materials should be addressed to D.M. (email: delphine.merino@onjcri.org.au) or to J.E.V. (email: visvader@wehi.edu.au) or to S.H.N. (email: naik.s@wehi.edu.au)
} 
a

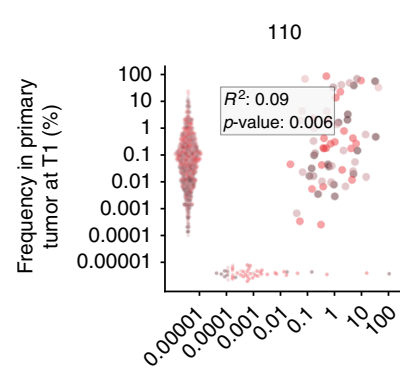

Frequency in lung at T3 (\%) b

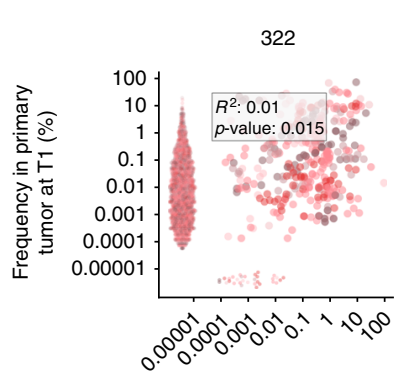

Frequency in lung at T3 (\%) c

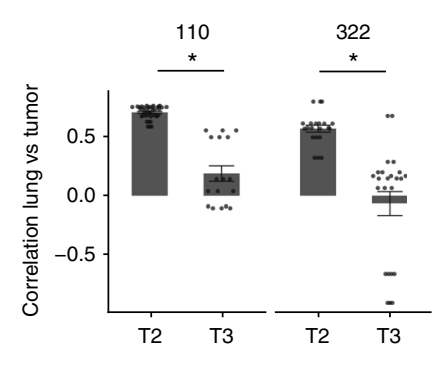

d

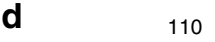

e

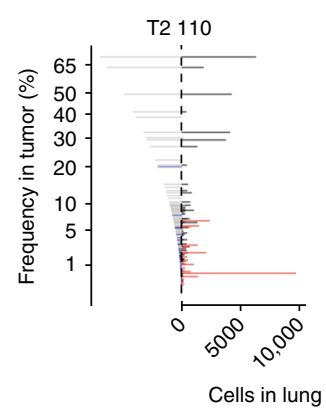

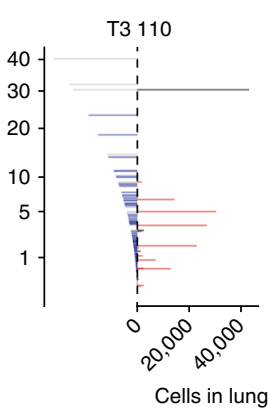

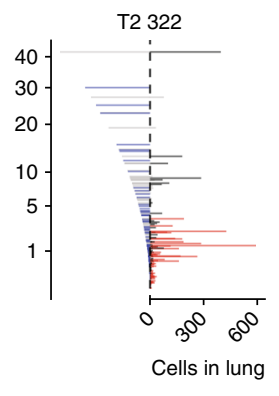

f

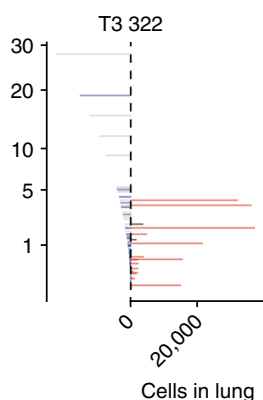

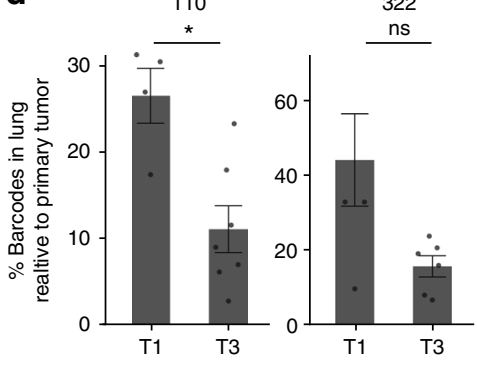

Fig. 1 